\title{
Machado: entre emulador e emulado
}

$\mathrm{A}$ O SE SUSTENTAR das insuficiências interpretativas que identifica, o debate crítico, mesmo o extenso, mostra a peculiar vitalidade que o amplia e renova. Acerca de Machado de Assis, não seria impróprio que a alguém soasse impossível a escrita de algo relevante hoje, dadas a quantidade e a qualidade dos estudos a ele destinados. Se existente, a sensação pode ser desfeita por Machado de Assis: por uma poética da emulação, de João Cezar de Castro Rocha.

O trabalho (integrante da "Coleção Contemporânea", coordenada por Evando Nascimento) se justifica como alternativa à suposta "crise dos quarenta anos" de Machado. Em seu lugar, sugere-se um período de profunda renovação - iniciado com a famosa crítica a $O$ primo Basílio, de Eça de Queirós, em 1878, desenvolvido por meio de leitura emuladora e estourado com a publicação de Memórias póstumas de Brás Cubas: "Daí, derivo a hipótese-chave deste ensaio: uma consequência imprevista da reação machadiana ao romance de Eça foi o resgate da noção clássica de aemulatio, que o levou a desenvolver a poética da emulação".

Quem lê João Cezar de Castro Rocha no jornal e no livro conhece-lhe a capacidade de conjuntar o micro e o macro, bem como o exitoso trânsito entre campos antípodas, que o faz levar densidade teórica à imprensa e imprimir despojamento na tese. No novo trabalho, ler sobre Machado de Assis é inteirar-se do dinamismo alterante dos papéis de hegemônico e periférico no jogo das culturas, e perceber sólido avanço sobre o que há

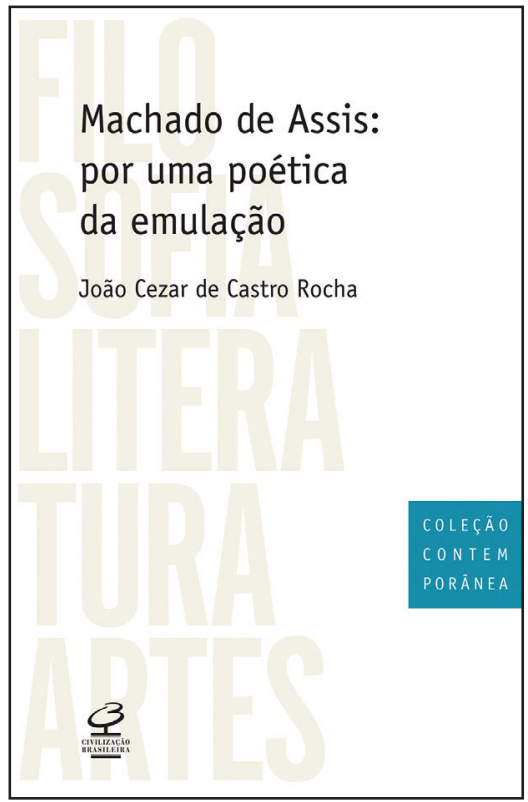

ROCHA, J. C. de C. Machado de Assis: por uma poética da emulação. Rio de Janeiro:

Civilização Brasileira, 2013.

de restritivo nos conceitos de influência, imitação e plágio. O erudito mosaico interpretativo vai de filósofos a enxadristas, reporta técnicas de apropriação literária, equipara-as à composição do hip-hop, e dá conta de um Machado inteiro, lido em vários textos, gêneros e épocas, e surpreendentemente investigado além da escrita: "O sistema literário Machado de Assis, e esse ponto é decisivo, não pode ser reconstruído exclusivamente com base na sua obra "visível"".

Sublinhe-se no crítico a escrita original. Ao correr das páginas, o percurso exegético é cheio de idas e vindas, com citações repetidas que, a cada aparição, destacam palavras diferentes, formando 
um campo semântico esclarecedor da ideologia machadiana, num movimento análogo ao do refrator oftalmológico. Veja-se, na terceira seção (o livro possui cinco, mais o introito e o desfecho), a espetacular montagem do subcapítulo "Auctoritas", e, em diversas outras partes, o caráter de autor-operário atribuído ao estudado e atribuível ao estudioso: "A organização inovadora de elementos preexistentes revela-se mais produtiva do que a ânsia pela criação de elementos novos, esclarecendo a centralidade da inventio na poética da emulação". É notória e notável a dicção isenta do gesso cientificista, especialmente estampada nos parágrafos curtíssimos, nos quais a reflexão ganha ares espontâneos, ao advertir a si mesma, ao dialogar com o leitor, ao reunir crítica e metacrítica e ao instilar conclusões que não prescindem do deboche: "(Temporária, não se esqueça, rima com precária: rima pobre, aliás.)". O conjunto dá ao trabalho riqueza formal e justeza ímpar, pois o autor contemplado também se notabilizou pelo emprego desses recursos. Noutros trabalhos, a escrita de João Cezar já carregava tais características, mas neste ela se radicaliza - estudo e objeto contaminados, crítica a falar sobve e como literatura.

João Cezar não se ajoelha diante do monumento, porque a contaminação aproximativa não significa anulação reflexiva. Concordando com a tese de duas fases machadianas (o que "nada tem a ver com o desejo escolar de nomeação de estilos de época ou de identificação de correntes literárias"), ele afirma, acerca da primeira, que "insistir numa possível ironia machadiana seria tapar o sol com a peneira". A despeito da autonomia intelectual e das reservas que faz à sua hipótese interpretativa (e o faz sem mero expediente retórico), o crítico, no esforço de demonstrar a intensidade do "pulo do gato" machadiano após a leitura de Eça, deixa de alcançar maior êxito ao insistir na grande distância que separa os "dois Machados". O corrente e depreciativo "Machadinho" "esclarece o traço definidor da primeira fase machadiana: forma convencional no romance e conteúdo conservador no conto - e vice-versa, pois, aqui, os termos são perfeitamente intercambiáveis".

A opinião se baseia com mais frequência nos Contos fluminenses e em $A$ mão e a luva. Não obstante sublinhe neles o exame da lógica do favor, João Cezar vê decoro excessivo nas obras, orientadas por "esquemas literários fabricados sob medida para as jovens senhoritas e as respeitáveis senhoras da corte de D. Pedro II". Sobre a crítica de Machado de Assis a O primo Basílio, aponta-se nas censuras do brasileiro um moralismo que condena as cenas lascivas do romance e não compreende a simbologia de personagens: "Luísa é mesmo um títere, mas nesse traço reside a força da crítica à falta de opção de uma jovem mulher na provinciana Lisboa oitocentista. Machado assinalou o ponto, mas não compreendeu seus desdobramentos".

Se João Cezar toma as peças do jogo de Machado para criticá-lo, tomem-se peças do crítico para medir alguns de seus juízos. Quando não é mero descritor e age para construir sentidos, um estudioso manifesta, sob outro matiz, a poética da emulação ("esforço deliberadamente anacrônico, desenvolvido especialmente em circunstâncias não hegemônicas", conceitua o livro). Assim um crítico, para tantos um ator secundário no espetáculo da literatura, extrapola o 
escanteio a que o relegam por encontrar liquidez onde tudo se havia cristalizado. Se o títere é força crítica, não haveria nos hipotéticos traços convencionais e conservadores de Machado alguma forma de desacordo com o status quo? Por que o "nossa heroína", com que o narrador de $A$ mão e a luva se refere à protagonista Guiomar, é apenas "identificação tranquilizadora" com os leitores? A "heroína” não salva, não doa, nem morre santificada como a Lucíola, de Alencar; rejeita ser chamada de "anjo" pelo noivo, preferindo "demônio", e, ao fim, seu heroísmo efetiva-se num sacramento ao gosto burguês: o casório com um homem ambicioso e de sobrenome opulento. Pouco antes da cerimônia, “[...] nada lhe lembrou o outro homem [Estêvão, de 'amor extático e romanesco'] que morria por ela. A felicidade é isto mesmo; raro lhe sobra memória para as dores alheias", relata o narrador.

Ao lado dos de seus conterrâneos contemporâneos, os quatro primeiros romances de "Machadinho" chancelarão o diminutivo? Para responder que não, recorro a Contos fluminenses, que toca com solidez nas inconstâncias humanas e com mordacidade nos predicados da "boa sociedade". De "O segredo de Augusta", lembro que a grandeza da socialite consistia em não pechinchar o valor das roupas, sobre o que diz seu fornecedor de tecidos - "Pedir um preço e dar a fazenda por outro preço menor é confessar que havia intenção de esbulhar o freguês" -, e sobre o que remata o narrador: "O fornecedor preferia fazer a cousa sem a confissão". Faço um porém, mas com um porém (a ser percebido no meu grifo): João Cezar destaca no livro o conto "Frei Simão", que para ele "apresenta elementos que serão marca registrada da segunda fase, embora se encontrem constrangidos por uma moldura tradicional'.

$\mathrm{Na}$ crítica de Machado a O primo Basílio, a censura maior recai sobre certo vácuo anímico da protagonista Luísa. Ali se defendeu que a repercussão do romance se devia mais à força da moda literária de então do que às suas qualidades estéticas, as quais Machado não negou. Em sua leitura, João Cezar aponta, a partir do vocabulário, um Machado purista, cujo “talento permanece refém da necessidade de atender às convenções da época”. Em paralelo à construção do campo semântico, o crítico investiga o léxico inexistente em Machado, e, pela comparação com Eça, chega à conclusão de um Machado castiço. A tarefa crítica solicita ir além do grafado, mas deve-se evitar a brusca inserção de uma perspectiva onde ela se mostra infértil. Pela óptica do realismo e do naturalismo (ou, apenas, pela óptica de Eça), Machado nunca foi um erótico, e não o foi por não se interessar pelo erotismo escancarado. No lugar disso, elaborou um moderno discurso de subentendidos - roupa enigmática de transparência e ocultamento -, que o alçou ao patamar dos maiores. Se tomado a rigor, talvez haja decoro em Eça: o capítulo XII de $O$ primo registra a grave altercação entre patroa e empregada: "Você manda-me calar, sua p...!' - E Juliana disse a palavra”. Que há no fragmento? Um atrevido "p" ou pudicas reticências?

João Cezar diz evitar ler toda a obra de Machado como se escrita pelo distinto autor das Memórias póstumas. Nelas, Machado atingiu um nível de construção formal a custo de estudo e exercício, mas as obras anteriores não são estranhas ao universo ficcional das Memórias, algo 
reconhecido por João Cezar: "Desse modo, se é necessário sublinhar as transformações internas do sistema literário Machado de Assis, é igualmente importante acentuar linhas complexas de continuidade". Ao longo do livro, no entanto, o leitor verá que a primeira ação é hegemônica sobre a segunda.

Por buscar a interpretação da obra invisível de Machado de Assis - em especial a leitura (de O primo Basílio) que o conduziu à renovação literária -, interessa procurar no livro de João Cezar o que ele deixa invisível: nas referências bibliográficas, aparecem todos os importantes intérpretes brasileiros (e brasilianistas) de Machado de Assis: Abel de Barros Baptista, Alfredo Bosi, Antonio Candido, John Gledson, Roberto Schwarz... A exceção recai sobre Ronaldes de Melo e Souza, autor de $O$ romance tragicômico de Machado de Assis (2006), tese seminal com que rejeita as duas fases da ficção machadiana, interpretando-a como contínuo adensamento da forma narrativa e da análise humana desde Ressurreição. Obviamente, não se exige do crítico a leitura de tudo, tampouco se lhe censura a liberdade de consulta. Mas o texto de orelha do livro de Ronaldes concorda com a necessidade de compreender a obra de Machado como um todo coerentemente organizado, e conclui dizendo que "este livro inovador está destinado a ocupar um lugar de destaque na crítica literária brasileira e desde já é leitura obrigatória para os estudiosos da obra machadiana". Por se tratar de uma orelha, tudo isso poderia ser nada, não fosse quem a assina: João Cezar de Castro Rocha.

Porém, como o próprio crítico diz, Machado construiu uma obra complexa, que permite a pluralidade de leituras crí- ticas, "questão prenhe de questões que nos levariam longe". Dada a longitude que alcança, Machado de Assis: por uma poética da emulação dá considerável contribuição aos estudos machadianos e à própria crítica literária brasileira, dentro da qual João Cezar de Castro Rocha figura como o mais importante nome surgido nos últimos vinte anos.
Marcos Pasche é doutor em Literatura Brasileira (UFRJ) e crítico literário, autor de De pedra e de carne: artigos sobre autores vivos e outros nem tanto (Confraria do Vento).

@ - marcos.pasche@bol.com.br

I Universidade Federal do Rio de Janeiro, Rio de Janeiro/RJ, Brasil. 